\title{
Green Tea Consumption and Stomach Cancer Risk in Women: A Meta-analysis of Population-Based Cohort Studies
}

\section{Jong-Myon Bae}

Department of Preventive Medicine, Jeju National University College of Medicine, Jeju, Korea

As numerous animal studies have shown that catechins as the main flavonoids presented in green tea are the active constituent for the anticancer activity, a hypothesis has been consistently suggested that green tea consumption would decrease the risk of stomach cancer [1]. In March 2020, Filippini et al. [2] reported results of a Cochrane Database of Systematic Review titled "Green tea (Camellia sinensis) for the prevention of cancer." The report showed no statistical significance of the association between green tea consumption and stomach cancer risk based on the result of meta-analysis from seven population-based cohort studies (summary relative risk [sRR], 0.99; 95\% confidence interval [CI], 0.85 to 1.14). The authors concluded that "a beneficial effect of green tea consumption on (stomach) cancer prevention remains unproven so far."

However, three of the seven selected cohort studies had followed up stomach cancer death. Thus, the additional meta-analysis was performed after excluding these three, in that the research hypothesis was to evaluate the association between green tea consumption and risk of stomach cancer occurrence. The result also showed no statistical significance but sRR was further away from 1 and the $95 \%$ CI was narrower (sRR, $0.93 ; 95 \%$ CI, 0.83 to 1.03). In addition, subgroup analysis was performed by sex. The statistical significance was not found in men (sRR, 1.11; $95 \%$ CI, 0.91 to 1.35), but in women (sRR, $0.81 ; 95 \%$ CI, 0.69 to 0.95 ) (Fig. 1). This finding suggested that green tea consumption in women would decrease the risk of stomach cancer.

As for the difference in the preventive effect of green tea between sexes, the difference in lifestyle such as smoking and drinking habit could be considered firstly [3]. However, other reasons such as hormonal therapy could be considered in that all cohort studies were adjusted for smoking and drinking habit [4]. Further research is needed for the difference.

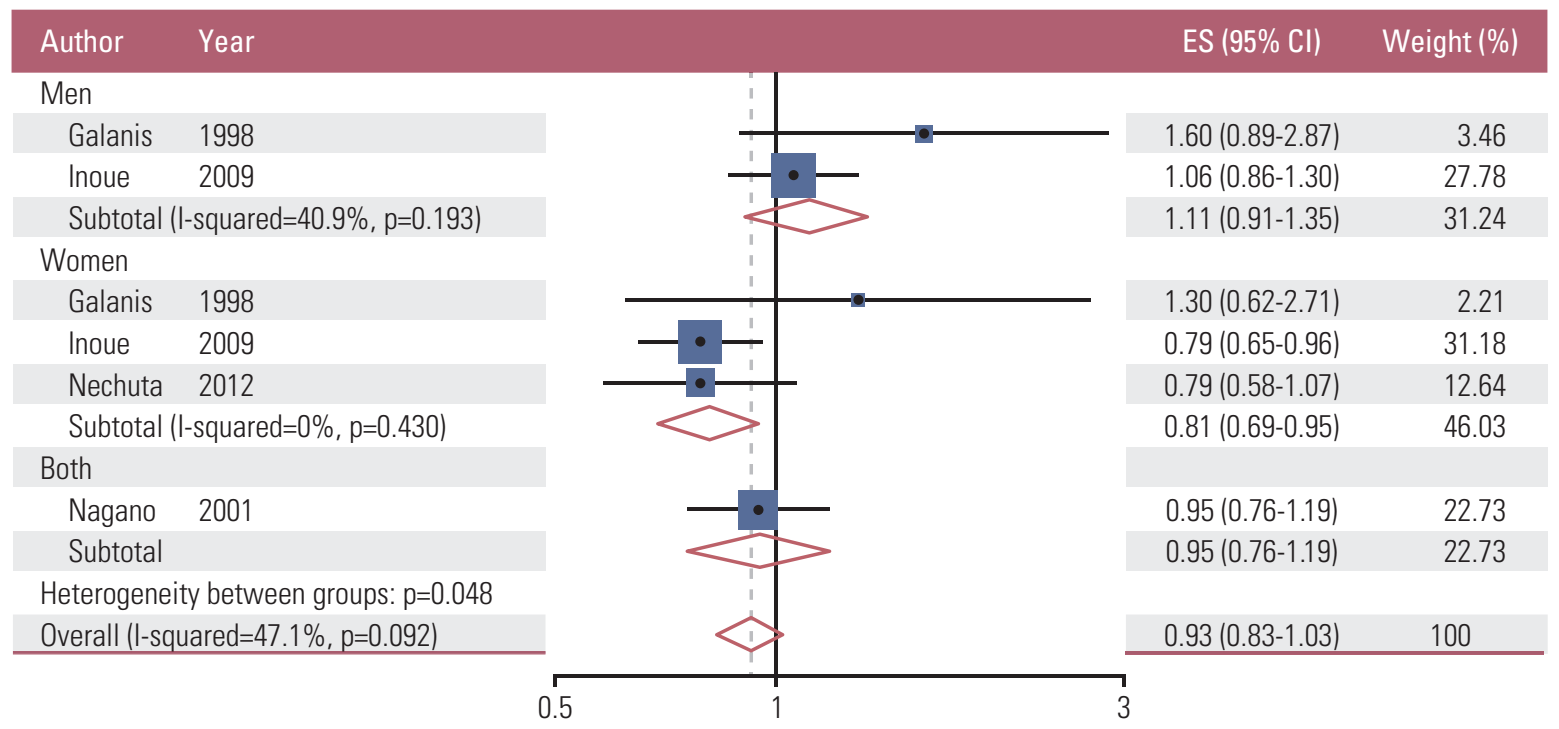

Fig. 1. Forest plot of estimating summary effect size (ES) by sex. CI, confidence interval. 


\section{Conflicts of Interest}

Conflict of interest relevant to this article was not reported.

\section{References}

1. Hou IC, Amarnani S, Chong MT, Bishayee A. Green tea and the risk of gastric cancer: epidemiological evidence. World J Gastroenterol. 2013;19:3713-22.

2. Filippini T, Malavolti M, Borrelli F, Izzo AA, Fairweather-Tait SJ, Horneber M, et al. Green tea (Camellia sinensis) for the prevention of cancer. Cochrane Database Syst Rev. 2020;3:CD005004.

3. Sasazuki S, Tamakoshi A, Matsuo K, Ito H, Wakai K, Nagata C, et al. Green tea consumption and gastric cancer risk: an evaluation based on a systematic review of epidemiologic evidence among the Japanese population. Jpn J Clin Oncol. 2012;42:335-46.

4. He Z, Zhao TT, Xu HM, Wang ZN, Xu YY, Song YX, et al. Association between alcohol consumption and the risk of gastric cancer: a meta-analysis of prospective cohort studies. Oncotarget. 2017;8:84459-72. 